International Journal of Research Studies in Electrical and Electronics Engineering (IJRSEEE)

Volume 6, Issue 2, 2020, PP 17-25

ISSN 2454-9346 (Online)

DOI: http://doi.org/10.20431/2454-9436.0602003

www.arcjournals.org

\title{
Throw-Over Transfer Switch for Digital Relay Protection and Automation Devices
}

\author{
Vladimir Gurevich, Ph.D. \\ Central Electrical Laboratory Israel Electric Corp., Haifa, Israel
}

*Corresponding Author: Vladimir Gurevich, Ph.D., Central Electrical Laboratory Israel Electric Corp., Haifa, Israel

\begin{abstract}
Critical kinds of relay protection and automation devices, used in the power industry need to be furnished with an automatic throw-over transfer switch (ATS) for changeover between power supply circuits. The efficiency of the design, based on diode-isolation between two sections of a substation (or power station) DC power auxiliary system, which was widely used for decades, is now questionable. The article suggests requirements for individual or group HEMP-resistant ATS and shows that factory-assembled ATS, which would meet these requirements, are not available on the market. The article also provides an analysis of switching elements for ATS working at 220V DC and suggests a description of a device, developed by the author, which meets the requirements.
\end{abstract}

Keywords: transfer switch, digital protection devices, HEMP, DC power auxiliary system

\section{INTRODUCTION}

Digital relay protection and automation devices (RPAD) used in the power industry are energized from two sections (DC1 and DC2) of a direct current auxiliary power system (DCAPS), both consisting of a battery charger $(\mathrm{BC})$ and a rechargeable battery $(\mathrm{RB})$.

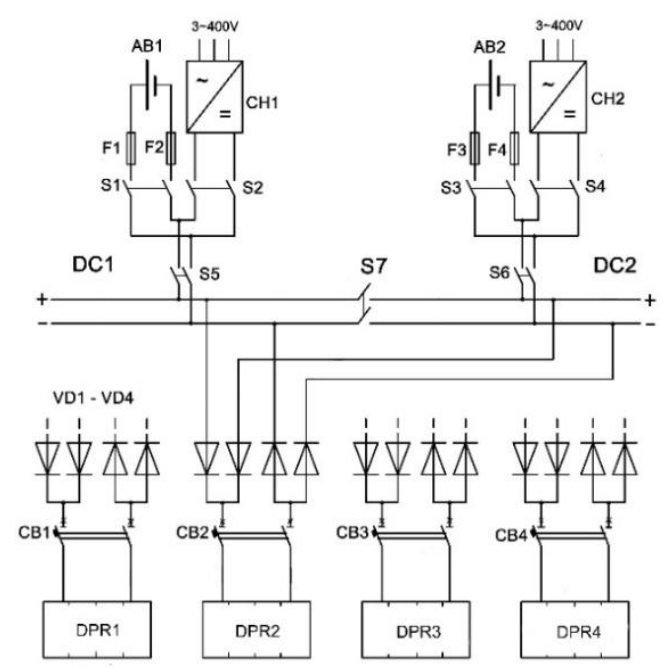

Figure1. Power supply of RPAD via 4 diodes, which ensure separation between positively and negatively charged poles of two sections (DC1 and DC2) of DCAPS. DPR-digital protection relays.

Under normal conditions, each of these systems powers its corresponding group of loads, but in case of BC or RB failure, they can be united by means of a manually operated throw-over switch (Fig. 1). As a result, any group of DC loads can be energized from any section of a DCAPS.

Some electronic devices employed in industrial RPAD are critical as they maintain operability and survivability of the power system, and thus they need to be furnished with an automatic backup power supply. 
According to [1], DCAPS must be equipped with a manually operated throw-over switch. However, [2] also suggests automatic throw-over for DC circuits, as well as connection of loads via separating diodes (cl. 8.6). Such diodes are widely used in auxiliary power supply circuits of RPAD in many countries. Figure 1 shows a simplified description of a so called "hot" throw-over by means of diodes commonly used in some countries. Each RPAD (or a group thereof) is energized from both sections of DC simultaneously. This technical solution is simple and efficient; it does not employ switching devices and ensures reliable throw-over in RPAD supply circuits.

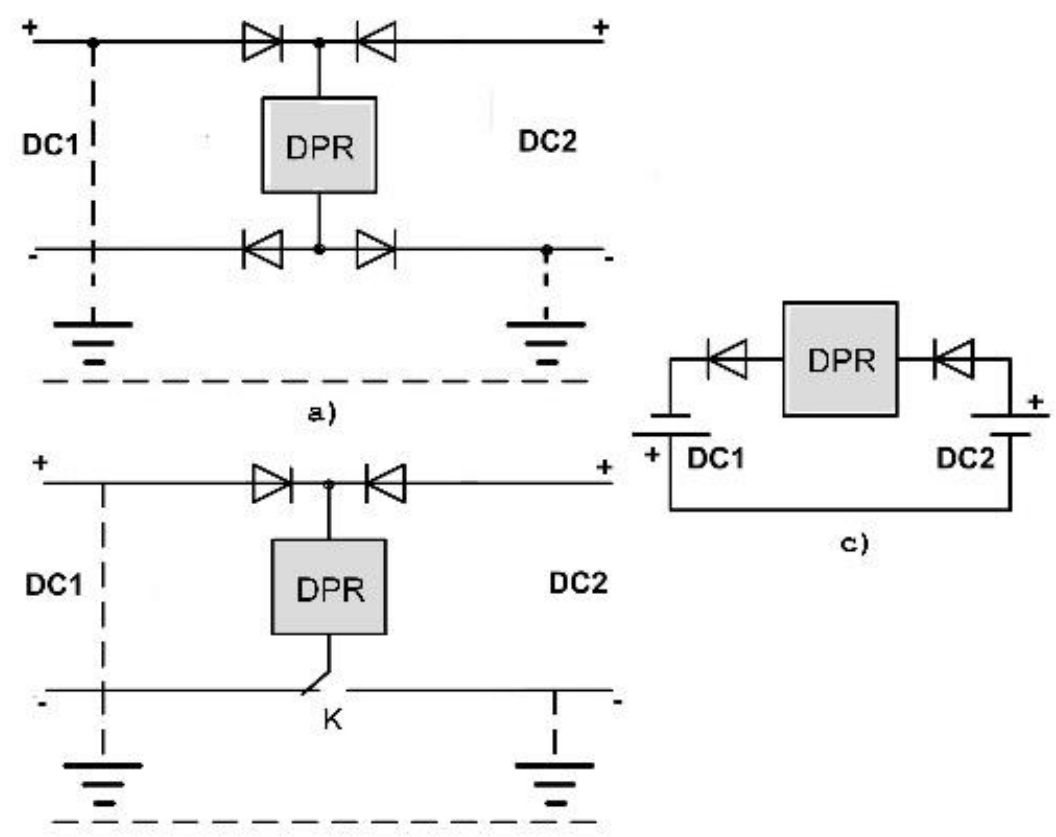

b)

Figure2. Simplified design of automatic throw-over using 4 diodes (a); combination of two diodes and a switching device (b); and an equivalent circuit (c).

Nevertheless, regardless of multiple advantages of this design, the result was far from perfect. There are many reports of practical use suggesting that this design resulted in massive failures of RPAD due to DC1 and DC2 voltage add up via diodes. Principally, this happens during maintenance or repair of DCAPS, or as a result of overlooked short circuit to the ground connected to one of the DC1's pole, and further unexpected short circuit to the ground connected to the opposite pole of DC2. In this situation, RPAD receives double voltage (about 450V) shown in Figure 2, resulting in failure of all devices affected by this voltage. Due to the high cost of contemporary digital RPAD and considering the consequences of sudden massive failures of multi-purpose RPAD, it becomes obvious that this design exposes the power system to hazards.

It is obvious from Figure 2 that replacement of one pair of diodes by the changeover contact switching device will not rescue the situation, thus, automatic throw-over must be ensured solely by switching devices without the use of diodes. Which switching devices do we really need? Since critical electronic devices used in the power industry must remain energized both under normal mode and in an emergency (subject to availability of corresponding protection means), such as impact of highaltitude electromagnetic pulse (HEMP) [3], the ATS should also be HEMP-resistant. This means that it should be solely built using electromechanical components (i.e. electromagnetic relay) and should not include microelectronics and microprocessor. At the same time, the contacts of these relays should ensure DC switching of several amperes at 220 VDC (at least).

What do we have in the market?

First of all, there are cabinet-type ATS, which include two large electromechanic contactors controlled by an electronic controller (Fig. 3). 


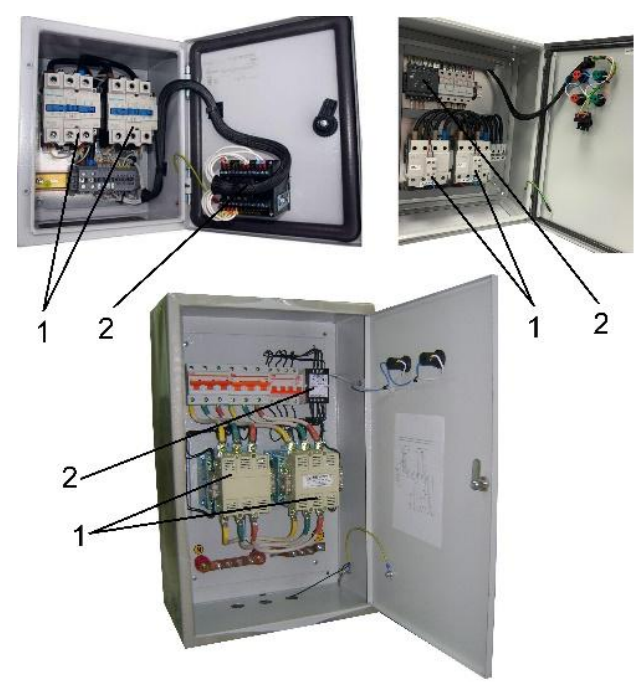

Figure3. Cabinet-type ATS, which include two powerful contactors 1 and controller 2.

Obviously, these ATS will not satisfy the requirements as they are too powerful and too large; they are designed for $\mathrm{AC}$ and include an electronic controller.

There are dozens of less powerful concise ATS manufactured in various countries of the world (Fig. 4). The only issue with them is that they are designed for AC circuits and are fitted with microelectronic and often microprocessor-based control units.



Figure4. Current low-power ATS for AC with a microelectronic control unit

Unfortunately, I managed to find only one type of fully electromechanic ATS (Fig. 5). But this is a too large and too heavy device for an alternating current.
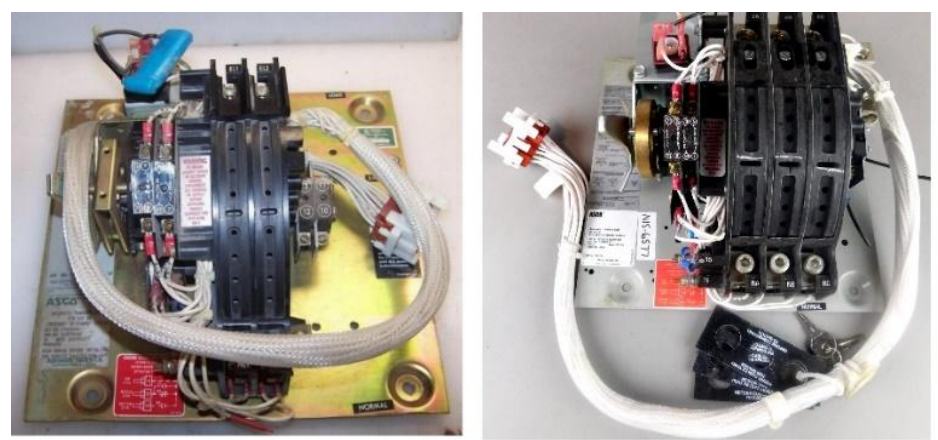

Figure5. Powerful two-pole (left) and three-pole (right) electromechanic ATS designed for current 230 A, manufactured by ASCO company

As for DC ATS, the situation is much worse. The market usually offers static ATS based on powerful IGBT-transistors with a microprocessor control (Fig. 6). These devices are quite large and expensive; they are designed for a current of dozens of amperes, and do not meet the abovementioned requirements. 


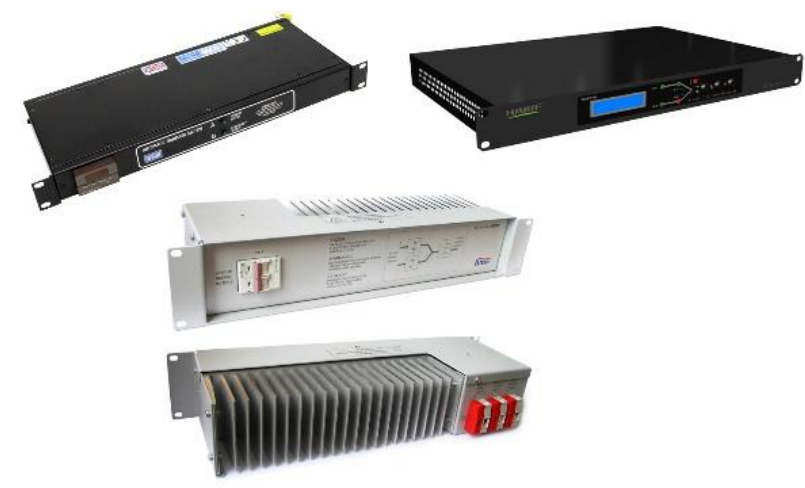

Figure6. Static switches for DC power supply systems

Unfortunately, I could not find complete ATS based on electromechanic elements designed for operation in DCAPS at 220 VDC. This necessitated development of my own design of ATS, suitable for supply circuits of critical relay protection and automation devices, including a special relay to ensure HEMP protection of a power transformer [4].

This ATS is quite space efficient, simple in terms of design, and operates based on three special electromagnetic relays intended for DC switching at $220 \mathrm{~V}$. These relays are less frequent than those designed for AC switching as the process of DC switching is different. Due to the lack of natural extinction of the electrical arc when the sinusoidal current passes through the zero value, as is the case with AC switching, the DC arc arising at the contacts of the switching device (relay) is able to quickly melt them.Thus, the switching ability of DC devices is usually much lower than that of AC devices (Fig. 7).

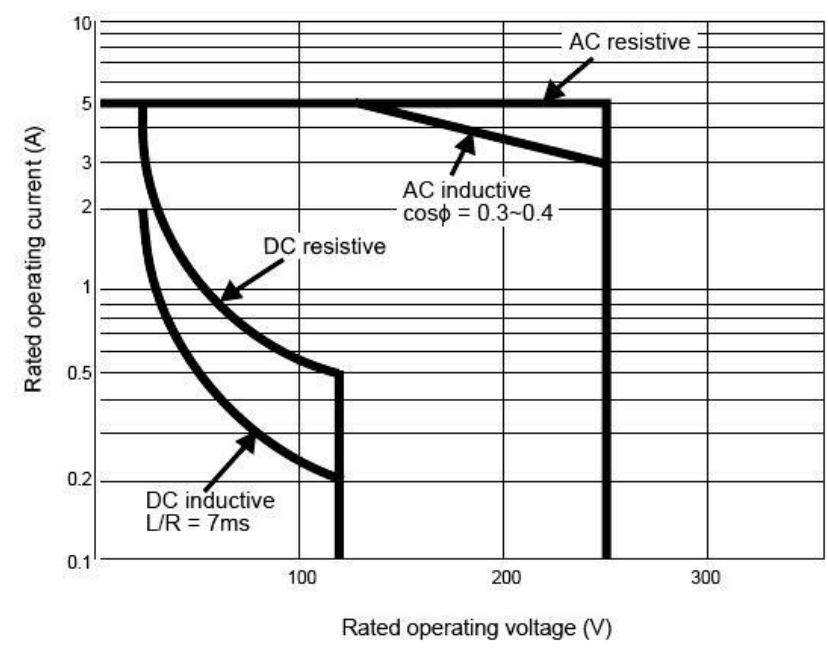

Figure7. Typical specification of the switching capacity of an electromagnetic relay with a maximum switching current of $5 \mathrm{~A}$ and a maximum switching voltage of $250 \mathrm{~V}$.

This difference is so significant that it does not permit the use of a common electromagnetic relay to act as switching elements in DC ATS devices. There are several technical solutions (or a combination thereof) for DC switching, e.g.:

- contacts with multiple disruptions (usually double make/break) or with connection of several common-type contacts in series;

- permanent magnets mounted close to contacts; they are responsible for arc blowout from the intercontact space;

- contacts placed into a hermetically sealed chamber filled with special gas under surplus pressure;

- contacts with two-stage switching containing a tungsten contact, which will be the first to close and the last to open, as well as an ordinary silver alloy contact, designed to bypass the tungsten contact. 


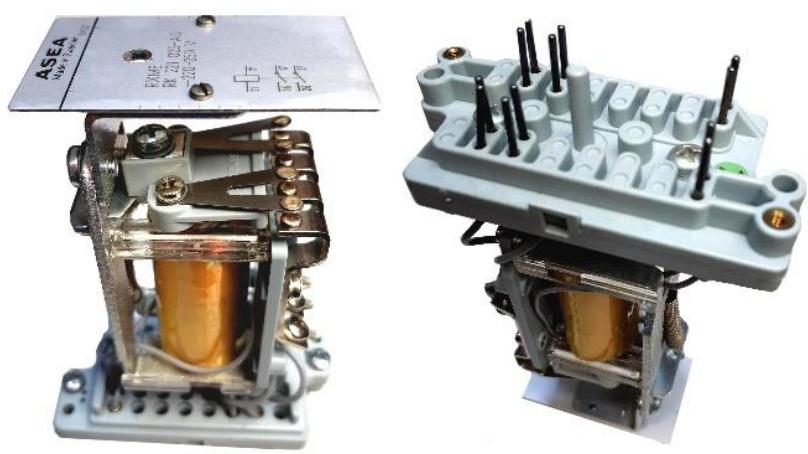

Figure 8. RXME1 (ASEA) relay with $V$-shape double make contacts specifically designed for switching in $220 \mathrm{~V}$ DC circuits.

The biggest spread in the power industry enjoy the contacts of the first type as they are simpler. For example, some 50 years ago ASEA company (foregoer of the contemporary leader in the field of power industry equipment - $\mathrm{ABB}$, which emerged as a result of merging of two leading companies: ASEA and Brown Bovery) manufactured a series of COMBIFLEX relays, which included many various types of electromagnetic relays with $\mathrm{V}$-shaped double make/break contacts (Fig. 8). Obviously, no one is going to use such devices in new projects. But what do we have instead?

ABB manufactures DC contactors containing three terminals connected in series through external S1 and S2 jumpers and a built-in permanent magnet (Fig. 9).

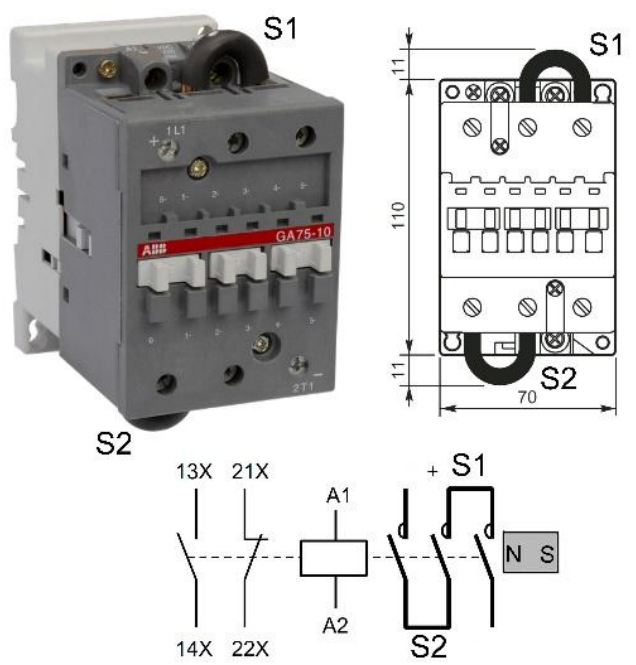

Figure9. GA75 type contactor $(A B B)$ designed for DC switching

Omron company manufactures hermetically sealed gas-filled relays, capable of switching currents rated dozens and hundreds of amperes at 220 VDC (Fig. 10). Unfortunately, these relays have only one NO contact and control coil for voltage up to $100 \mathrm{~V}$.

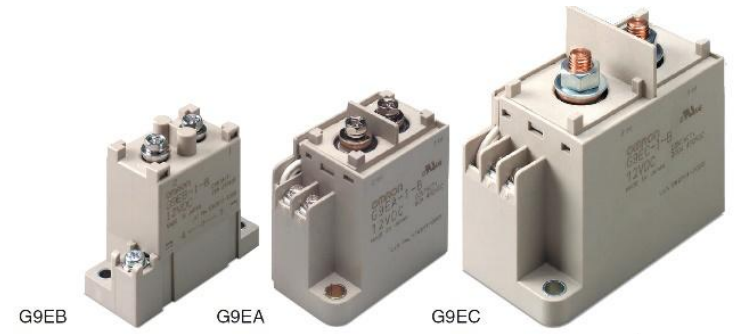

Figure10. Powerful relays manufactured by Omron company for DC switching at voltage levels of up to $400 \mathrm{~V}$.

Simultaneously, our analysis revealed many small size electromagnetic relays designed for DC switching at 220V (Table 1). There are samples among these devices which are quite suitable (in terms of contacts type and switching ability) for use in the offered ATS. In particular, I chose the 
PT570220 relay manufactured by Schrak company to act as a control relay (K1, Fig. 11), and the MKS2XT-11DC220 type relay manufactured by Omron company to act as switching elements (K2 and $\mathrm{K} 3$ ).

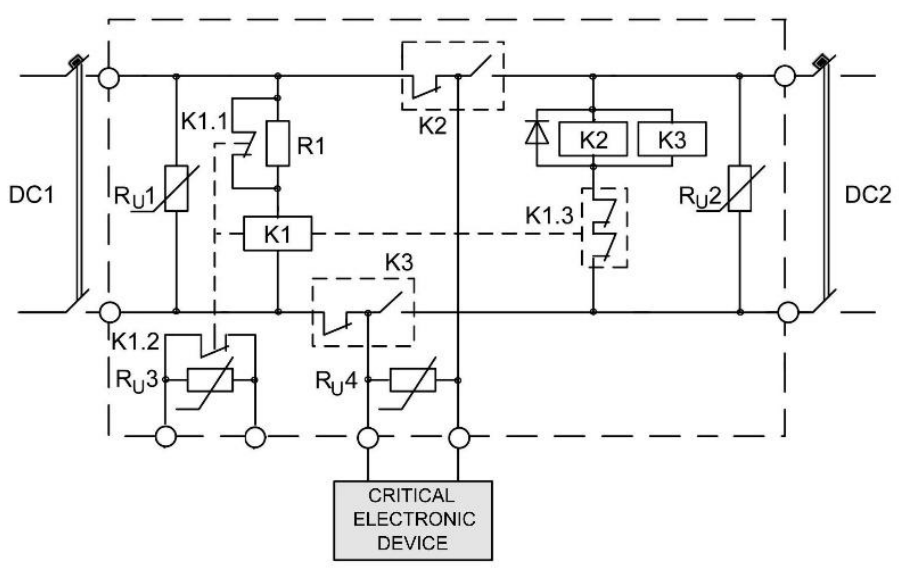

Figure11. Circuit diagram of developed DC ATS

Table1. Contacts arrangements and switching capabilities of electrical relays intended for DC load

\begin{tabular}{|c|c|c|c|c|}
\hline Relay Type & Manufacturer & Contacts Type & $\begin{array}{l}\text { Switching } \\
\text { Capacity at } \\
\text { 220VDC } \\
\end{array}$ & $\begin{array}{c}\text { Load Type } \\
\text { IEC 60947-4-1 } \\
\text { IEC 60947-5-1 } \\
\end{array}$ \\
\hline \multirow{3}{*}{$\begin{array}{l}\text { MKS2XT- } \\
11 \mathrm{DC} 220\end{array}$} & \multirow{3}{*}{ Omron } & \multirow{3}{*}{$\begin{array}{c}1 \mathrm{NO}+1 \mathrm{NC} \\
\text { double make/break with } \\
\text { magnet blow-out }\end{array}$} & $\mathrm{NO}-10 \mathrm{~A} ; \mathrm{NC}-5 \mathrm{~A}$ & DC1 \\
\hline & & & $\mathrm{NO}-5 \mathrm{~A} ; \mathrm{NC}-3 \mathrm{~A}$ & $\mathrm{~L} / \mathrm{R}=7 \mathrm{~ms}$ \\
\hline & & & $\begin{array}{c}\mathrm{NO}-0.4 \mathrm{~A} ; \mathrm{NC}- \\
0.1 \mathrm{~A}\end{array}$ & DC13 \\
\hline \multirow{3}{*}{ MT series } & \multirow{3}{*}{ Schrack } & \multirow{3}{*}{$2 \mathrm{CO} ; 3 \mathrm{CO}$} & single $-0.25 \mathrm{~A}$ & \multirow{3}{*}{ DC1 } \\
\hline & & & 2 in series $-0.5 \mathrm{~A}$ & \\
\hline & & & 3 in series $-0.8 \mathrm{~A}$ & \\
\hline \multirow{2}{*}{$\begin{array}{l}\text { REL-PR1- } \\
\text { 220DC }\end{array}$} & \multirow{2}{*}{$\begin{array}{l}\text { Phoenix } \\
\text { Contacts }\end{array}$} & \multirow{2}{*}{$\begin{array}{c}1 \mathrm{NO} \\
\text { magnet blow-out }\end{array}$} & $1 \mathrm{~A}$ & DC13 \\
\hline & & & $3 \mathrm{~A}$ & $\mathrm{~L} / \mathrm{R}=40 \mathrm{~ms}$ \\
\hline $\begin{array}{l}\text { REL-OR/LDR- } \\
\text { 220DC }\end{array}$ & $\begin{array}{l}\text { Phoenix } \\
\text { Contacts }\end{array}$ & $\begin{array}{c}1 \mathrm{NO} \\
(2 \text { contacts in series } \\
\text { connection) }\end{array}$ & $0.3 \mathrm{~A}$ & DC13 \\
\hline \multirow{4}{*}{ PT series } & \multirow{4}{*}{ Schrack } & \multirow{4}{*}{$2 \mathrm{CO} ; 3 \mathrm{CO} ; 4 \mathrm{CO}$} & single $-0.4 \mathrm{~A}$ & \multirow{4}{*}{ DC1 } \\
\hline & & & 2 in series $-0.6 \mathrm{~A}$ & \\
\hline & & & 3 in series $-0.8 \mathrm{~A}$ & \\
\hline & & & 4 in series $-1.2 \mathrm{~A}$ & \\
\hline \multirow{2}{*}{$\begin{array}{l}\text { C3-X10 } \\
\text { C5-X10 } \\
\text { C7-X10 }\end{array}$} & \multirow{6}{*}{ Releco } & \multirow[b]{2}{*}{$1 \mathrm{NO}$ (double make) } & $1.2 \mathrm{~A}$ & DC1 \\
\hline & & & $0.3 \mathrm{~A}$ & DC13 \\
\hline \multirow[b]{2}{*}{$\mathrm{C} 4-\mathrm{X} 20$} & & \multirow{2}{*}{$\begin{array}{c}2 \mathrm{NO} \\
\text { (double make each) }\end{array}$} & $1.2 \mathrm{~A}$ & DC1 \\
\hline & & & $0.3 \mathrm{~A}$ & DC13 \\
\hline \multirow{2}{*}{$\begin{array}{l}\text { C3-M10 } \\
\text { C5-M10 }\end{array}$} & & \multirow{2}{*}{$\begin{array}{c}1 \mathrm{NO} \text { (double make } \\
\text { with magnet blow-out) }\end{array}$} & $10 \mathrm{~A}$ & DC1 \\
\hline & & & $2 \mathrm{~A}$ & DC13 \\
\hline RMC & Schrack & $\begin{array}{c}1 \mathrm{NO}+1 \mathrm{NC} \\
\text { double make/break }\end{array}$ & $0.8 \mathrm{~A}$ & DC1 \\
\hline RME2AN-FT & \multirow{4}{*}{$\begin{array}{l}\text { Relequick S. A. } \\
\text { (relays coils } \\
\text { up to } 115 \mathrm{VDC} \text { ) }\end{array}$} & $2 \mathrm{NO}$ & $1 \mathrm{~A}$ & DC1 \\
\hline RME3AN-FT & & $3 \mathrm{NO}$ & $1 \mathrm{~A}$ & DC1 \\
\hline RME1DN-FT & & 1NO (double make) & $3 \mathrm{~A}$ & DC1 \\
\hline RME1TN-FT & & 1NO (triple make) & $5 \mathrm{~A}$ & DC1 \\
\hline \multirow{2}{*}{ UF series } & \multirow{5}{*}{ Kuhnke } & $1 \mathrm{CO}(2$ in series $)$ & $0.3 \mathrm{~A}$ & DC1 \\
\hline & & $1 \mathrm{CO}$ (3 in series) & $0.6 \mathrm{~A}$ & DC1 \\
\hline \multirow[b]{2}{*}{105 type } & & $2 \mathrm{NO}+2 \mathrm{NC}$ & $0.3 \mathrm{~A}$ & DC1 \\
\hline & & $\begin{array}{c}1 \mathrm{NO}+1 \mathrm{NC} \\
(2 \mathrm{NO}+2 \mathrm{NC} \text { in series })\end{array}$ & $0.6 \mathrm{~A}$ & DC1 \\
\hline P type & & $1 \mathrm{NO}$ & 1.8 & DC1 \\
\hline
\end{tabular}




\begin{tabular}{|c|c|c|c|c|}
\hline & & $\begin{array}{l}\text { (double make with } \\
\text { magnet blow-out) }\end{array}$ & & \\
\hline \multirow{2}{*}{ D-B } & \multirow{8}{*}{$\begin{array}{c}\text { NieafSmitt } \\
\text { B. V. }\end{array}$} & \multirow{2}{*}{$\begin{array}{c}4 \mathrm{CO} \\
\text { (magnet blow-out) }\end{array}$} & $3 \mathrm{~A}$ & DC1 \\
\hline & & & $1 \mathrm{~A}$ & $\mathrm{~L} / \mathrm{R}=40 \mathrm{~ms}$ \\
\hline \multirow{2}{*}{ D-YB } & & \multirow{2}{*}{$\begin{array}{c}2 \mathrm{CO} \\
\text { (double make/break } \\
\text { with magnet blow-out) }\end{array}$} & $4 \mathrm{~A}$ & $\mathrm{DC} 1$ \\
\hline & & & $2 \mathrm{~A}$ & $\mathrm{~L} / \mathrm{R}=40 \mathrm{~ms}$ \\
\hline \multirow{2}{*}{ D-BX5 } & & \multirow{2}{*}{$\begin{array}{c}2 \mathrm{NO}+2 \mathrm{NC} \\
(\text { magnet blow-out) }\end{array}$} & $5 \mathrm{~A}$ & DC1 \\
\hline & & & $3 \mathrm{~A}$ & $\mathrm{~L} / \mathrm{R}=40 \mathrm{~ms}$ \\
\hline \multirow{2}{*}{ D-YBX5 } & & \multirow{2}{*}{$\begin{array}{c}1 \mathrm{NO}+1 \mathrm{NO} \\
\text { (double make/break } \\
\text { with magnet blow-out) }\end{array}$} & $6 \mathrm{~A}$ & $\mathrm{DC} 1$ \\
\hline & & & $4 \mathrm{~A}$ & $\mathrm{~L} / \mathrm{R}=40 \mathrm{~ms}$ \\
\hline DRH174220LT & \multirow[t]{2}{*}{ Weidmuller } & $\begin{array}{c}1 \mathrm{NO} \text { or } 1 \mathrm{NC} \\
\text { (double make/break } \\
\text { with magnet blow-out) }\end{array}$ & $7 \mathrm{~A}$ & DC1 \\
\hline DRH275220LT & & $\begin{array}{c}1 \mathrm{NO}+1 \mathrm{NC} \\
\text { (magnet blow-out) }\end{array}$ & $2 \mathrm{~A}$ & DC1 \\
\hline
\end{tabular}

The idea behind the ATS circuit (Fig. 11) is that the main switching elements (K2 and K3 relay) are de-energized in the standby mode. Whereas the K1 relay, though permanently connected, remains in the light mode due to the 5W R1 resistor connected in series with the coil of the K1 relay upon its actuation. With 22 kiloohm resistance of the resistor, the voltage on the relay's coil under long-term service will not exceed $175 \mathrm{~V}$ at the circuit voltage of $230 \mathrm{~V}$. The release voltage of this relay with the resistor will be about $70 \mathrm{~V}$.

This device is also fitted with varistors connected parallel to all inputs and outputs, which ensure additional HEMP protection of both the ATS and external circuits connected thereto. The device is mounted in a small plastic casing designed for mounting on a standard DIN-rail or a panel (Fig. 12). Due to relatively large switching ability of MKS2XT-11DC220 relays, this device can be used both as an individual ATS, and as common ATS for a group of electronic devices with a total current consumption of up to $5 \mathrm{~A}$ at $220 \mathrm{~V}$ (current consumption of single contemporary digital protection relays does not exceed $0.2-0.3 \mathrm{~A}$ at $220 \mathrm{~V}$ ). The current of $5 \mathrm{~A}$ is the switching current of the NO relay contacts. Its NC contacts (see Table 1) can emit $2 \mathrm{~A}$ only. Both types of contacts take part in throw-over, yet $\mathrm{NC}$ contacts open a de-energized circuit only upon outage of the DC1 voltage. The purpose of these contacts is to prevent voltage of the DC2 section from entering the circuits, the loads in the $\mathrm{DC} 1$ section and the $\mathrm{K} 1$ relay. That is why the switching ability of the device will be a function of the NO contacts' switching ability. In addition, two series NO and two series NC contacts (one set in positive and one set in the negative pole of the DC circuit) are used for changeover power in the developed device that increase switching ability.



Figure12. Prototype of developed ATS 
Another version of the ATS for increased load circuit, based on relay of the same type (MKS2XT11DC220) is shown in Fig. 13. In this circuit, only the NO contacts of this relay are used in the load circuit, which allow a higher carry current than the NC contact, used in the previous circuit.



Figure13. Another version of the ATS for increased load circuit

There can be a short-term power interruption on electronic devices at the moment of throw-over of internal ATS relays. The research showed that this power interruption does not last longer than $32 \mathrm{~ms}$ for the device described above (Fig. 14).

This power interruption in relay protection and automation devices does not usually result in failures or malfunctions. According to the IEC Standard [5], these devices should be failsafe during power interruption lasting from $10 \mathrm{~ms}$ to $1 \mathrm{~s}$ (subject to the manufacturer's discretion). The actual measured power interruption for multiple types of digital relay protection devices manufactured by the leading Western manufacturers are no less than $1.2-3.8 \mathrm{~s}$. Special relay, which ensures HEMP protection of a power transformer [4], remains in service for $1.02 \mathrm{~s}$ upon power interruption. This is efficient to ensure uninterrupted power supply by means of the described above ATS.

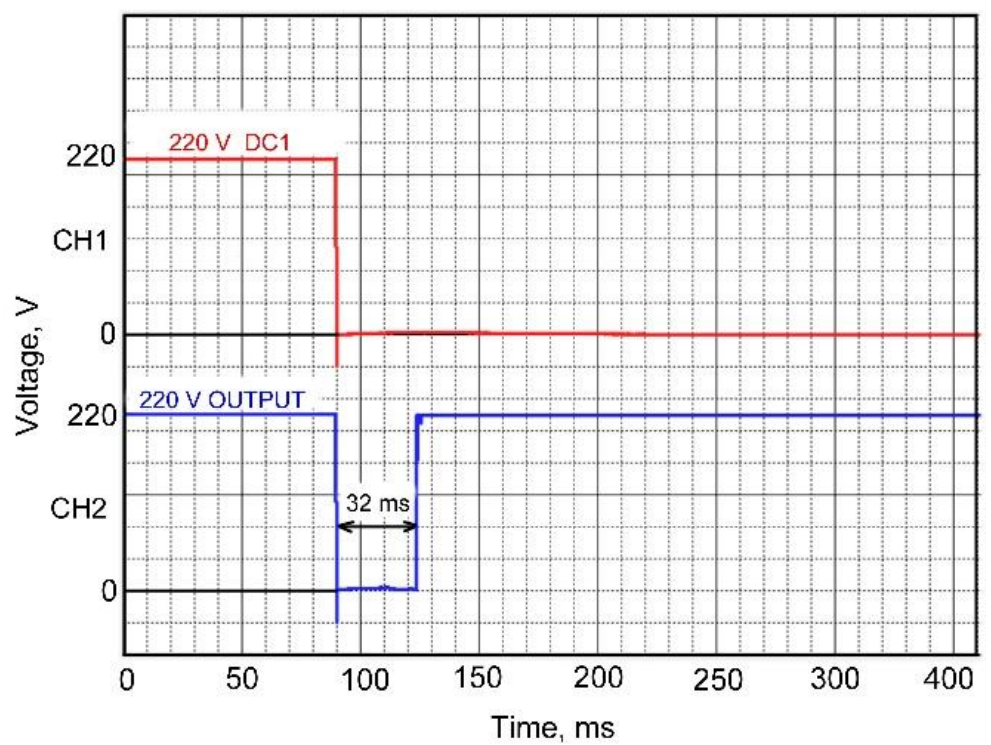

Figure14. Oscillogram of throw-over process in the developed ATS

For rare and unlikely cases, when the load (electronic or another device) does not support any power interruption, even as short as $32 \mathrm{~ms}$ required for ATS operation, there is a special unit [6] which sustains power in the load for the duration of this specific period (Fig. 15). 

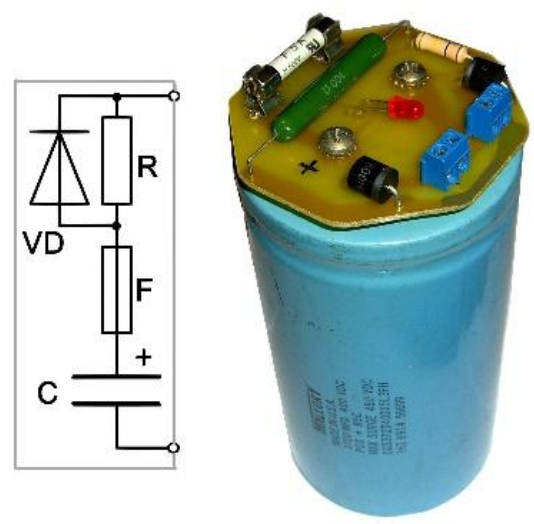

Figure15. Special unit sustaining power for the period of ATS operation in specific loads, which do not permit even short-term power interruptions.

This unit is manufactured based on a large capacitor $(3,700 \mu \mathrm{F}, 400 \mathrm{~V})$ fitted with a high interrupting duty fuse, resistor and diode. In this circuit, when the capacitor switches on it is charged via a resistor limiting the charging current at $1-2$ amperes, whereas the discharge runs directly via the power VD diode. This circuit prevents the capacitor from creating current surges which can result in automatic switches actuation. On the other hand, it ensures rather high current, which is necessary to supply the loads during the period required for throw-over of internal ATS relays.

\section{REFERENCES}

[1] Auxiliary DC System Design Guide STO 56947007-29.120.40.093-2011 (ODS) ENES. Typical design decisions. - Organization standard OAO FGC UES, Moscow, 2011 (in Russian).

[2] Auxiliary DC System of Substations STO 56947007-29.120.40.041-2010. Technical requirements. Organization standard. OAO FGC UES, Moscow, 2010 (in Russian).

[3] Gurevich V. Protecting of Electric Equipment: Good Practices for Preventing High Altitude Electromagnetic Pulse Impacts. - De Gruyter, Berlin, 2019, 386 p.

[4] Gurevich V. Protection of Power Transformer from High Altitude Electromagnetic Pulse. - International Journal of Research Studies in Electrical and Electronics Engineering, 2020, Vol. 6, Issue 1, pp.17 - 24.

[5] IEC 60255-1. Measuring relays and protection equipment - Part 11: Voltage dips, short interruptions, variations and ripple on auxiliary power supply port.

[6] Gurevich V. Power Supply Devices and Systems of Relay Protection. - CRC Press, Boca Raton - London New York, 2014, 248 p.

Citation: Vladimir Gurevich (2020)" Throw-Over Transfer Switch for Digital Relay Protection and Automation Devices, International Journal of Research Studies in Electrical and Electronics Engineering (IJRSEEE), 6(2), pp.17-25, DOI: http://doi.org/10.20431/2454-9436.0602003

Copyright: () 2020 Vladimir Gurevich. This is an open-access article distributed under the terms of the Creative Commons Attribution License, which permits unrestricted use, distribution, and reproduction in any medium, provided the original author and source are credited 